\title{
Assessment of Cowpea (Vigna unguiculata (L.) Walp.) Mutant Lines for Drought Tolerance
}

\author{
Karidiatou Gnankambary, ${ }^{1}$ Nerbéwendé Sawadogo (iD, ${ }^{2}$ Zakaria Diéni, ${ }^{1}$ \\ Téyouré Benoit Joseph Batieno, ${ }^{1}$ Jean Baptiste De Salle Tignegré, ${ }^{1}$ \\ Mahamadou Sawadogo, ${ }^{2}$ and Tinga Jeremy Ouédraogo ${ }^{1}$ \\ ${ }^{1}$ Institut de l'Environnement et de Recherches Agricoles (INERA), CNRST, 01 BP 476, Ouagadougou 01, Burkina Faso \\ ${ }^{2}$ Equipe Génétique et Amélioration des Plantes/Laboratoire Biosciences, Ecole Doctorale Sciences et Technologies, \\ Université Ouaga 1 Professeur Joseph KI- ZERBO, 03 BP 7021, Ouagadougou 03, Burkina Faso
}

Correspondence should be addressed to Nerbéwendé Sawadogo; nerbewende@yahoo.fr

Received 25 June 2020; Revised 4 September 2020; Accepted 25 September 2020; Published 10 October 2020

Academic Editor: Mehdi Rahimi

Copyright (C) 2020 Karidiatou Gnankambary et al. This is an open access article distributed under the Creative Commons Attribution License, which permits unrestricted use, distribution, and reproduction in any medium, provided the original work is properly cited.

\begin{abstract}
Cowpea provides the cheapest source of protein with an average range of protein content of $23-30 \%$. However, cowpea growth, development, and yield are greatly affected by drought during flowering and pod filling in the sub-Sahelian areas. The best way to cope with this situation is to develop drought-tolerant cowpea varieties. The objective of this study was therefore to evaluate cowpea lines developed through mutagenesis using gamma radiation to assess their reaction under optimal and water-stressed conditions. The response of ten mutants-irradiated Moussa local was then evaluated in pots arranged in a split plot design in a screen house. Two conditions were applied with optimum and water-stressed conditions. The stress was applied for two weeks at flowering. Two cowpea varieties Gorom local (drought-tolerant) and Moussa local (susceptible) nonirradiated were used as checks. Thereafter, field trials under two different sowing dates were conducted to identify the best tolerant mutant line(s) using agromorphological and tolerance indicators. The results indicated that mutant lines (MoussaM51-4P10 and MoussaM43-20P14) exhibited better stress tolerance and produced higher yield under water stress conditions. Stress Tolerance Index (STI) was better to select cowpea mutant tolerant with higher yielding under moderate stress $(\mathrm{SI}=35 \%)$. The study confirmed that water stress has a negative effect on cowpea seeds production and on leaf chlorophyll content. The high temperature during experiment increased water stress effect mainly on non-irradiated checks (Gorom local and Moussa local).
\end{abstract}

\section{Introduction}

Cowpea (Vigna unguiculata) is grown throughout tropical and subtropical regions. About 6.5 million metric tons of cowpea is produced annually on 14.5 million hectares in the world [1]. Africa accounts for $96 \%$ of grain production and more than $87 \%$ for West Africa [2]. In sub-Saharan Africa, the first cowpea producers are Nigeria and Niger recording $80 \%$ of total production [1]. Burkina Faso stands third after Niger and Nigeria in West Africa group with 5.8 million metric tons of cowpea grains annually [2]. Cowpea contains the high proportion of protein. While in sub-Saharan Africa, cowpea yield remains one of the lowest among all grain legumes due to many constraints as the drought. In this region, rainfall comes late, is sparse, or stops earlier than usually required. Rainfall declining is frequently recorded since the 1960s [3] and in magnitude over the past 50 years [4]. Therefore, it limits agricultural productivities [5]. Water deficit occurring during reproductive stage of cowpea plant limits cowpea growth and seed yield $[6,7]$. Indeed, it induces significant alterations in plant physiology and biochemistry, reducing the water content of plant leaves and total chlorophyll. Most cowpea breeding programs for tolerance to drought used conventional breeding methods exploiting only the natural variability available. The selection within germplasm for a long time exhausted the genetic variability 
of the legume crop [8]. Adequate variability is not available to improve cowpea production because of the lower genetic pool [9]. The development of new varieties tolerant to water stress with high yield is therefore important to anticipate cowpea yield losses. Mutation breeding is an alternative solution to producing variant mutant form. Induced mutation can be efficiently used as an alternative to induce genetic variability [10]. For quite a long time now, the use of mutagens has been proven to be beneficial in cowpea [11] and in groundnut [12]. In Burkina Faso, gamma-ray mutation has been used to broaden the genetic base of cowpea. These works showed that $150 \mathrm{~Gy}$ dose induced genetic variability in cowpea $[13,14]$. Moreover, gamma radiation is a way to enhance crop tolerance to drought [15]. The objective of this study was to evaluate M5 and M6 generations of cowpea mutant lines issued from irradiation with gamma ray to drought.

\section{Materials and Methods}

2.1. Materials and Site Description. This study was conducted in a screen house at Kamboinsé research station in Burkina Faso and in field condition at Kouare research station. Kamboinsé is in the center of Burkina Faso close to Ouagadougou, the capital, and between $12^{\circ} 26^{\prime} 59.4^{\prime}$ longitude north and $1^{\circ} 33^{\prime} 08.0^{\prime}$ latitude west. The period from March to May corresponds to the highest temperatures $\left(35-43^{\circ} \mathrm{C}\right)$ recorded in the country with lower relative humidity. The Kouare research station is in the eastern Burkina Faso between $11^{\circ} 39.055^{\prime}$ north longitude and $000^{\circ} 18.489$ west latitude. In this locality, rain starts mainly in June and ends in October with maximum rainfall in August. From September to October, extremely low rainfalls are recorded. The annual rainfall varies from 600 to $800 \mathrm{~mm}$. In general, Burkina Faso is characterized by a semiarid climate with large seasonal variation in rainfall.

Ten M4 mutants obtained from irradiated Moussa local (humidity content of $8 \%$ ) using gamma radiation at $150 \mathrm{~Gy}$ were developed on single plant descent selection method (Figure 1) at Kamboinsé. From these, lines were therefore advanced to M5 and M6.

Moussa local is cowpea variety developed by INERA. Seeds were packaged in a batch of $500 \mathrm{~g}$. Seeds irradiation was supported by the laboratory of the International Atomic Energy Agency (IAEA) of Seibersdorf, Austria. The source of gamma radiation was marked cobalt (60CO). The dose $150 \mathrm{~Gy}$ was chosen because germination assays indicated that 150 Gy corresponded to the optimal dose which induced $50 \%$ of seed germination of this variety.

The M5 and M6 generation lines were then evaluated under well-watered and water-stressed screen house and field conditions, respectively. M5 lines were evaluated under screen house at Kamboinsé. M6 lines were then evaluated under field conditions at Kouare. Gorom local was used as resistant check and Moussa local was the susceptible check [16]. The main characteristics of Gorom local are its medium maturity and high-yield potential [7] but Moussa local has low yield potential [16].

\subsection{Methodology}

2.2.1. Pot Experiments. Ten M4 mutants were carried out in screen house experiments. The trial was planted in pot (10l) arranged in a split plot design, with the water regime being the main factor and the genotypes being the subplots. Each water regime was replicated twice. Pots were filled with $10 \mathrm{~kg}$ of soil composed of $83.3 \%$ sand; $9.50 \%$ clay; and $5.78 \%$ silt (Saria Soil Laboratory). One cowpea seed was planted by pot on 17th of March 2018. Soil moisture level for the two treatments was maintained at field capacity corresponding to $1.5 \mathrm{l}$ of water. For the water stress regime treatment, plants were exposed to water stress 43 days after planting (DAP) corresponding to days to $50 \%$ flowering. Pot rewatering was (field capacity) resumed after 14 days' drought imposition. NPK fertilizer (14-23-14) at the rate of $100 \mathrm{Kg} / \mathrm{ha}$ was applied two weeks after planting. Insects' control was done using Deltacal 12.5 EC (deltamethrin) and K-optimal 12.5 EC (deltamethrin + dimethoate) at flowering and pod formation, respectively.

2.2.2. Field Experiments. Sixteen M5 lines were carried out in field's experiments. Six promising mutant lines with improved drought tolerance were selected by plant from M5 generation tested in screen house and eight mutant lines M5 were obtained by multiplication. Gorom local and Moussa local were used as nonirradiated checks. The experiments were led out in a randomized complete block design with factorial combination of two planting dates, July 25 and August 21, 2018. Three replications were established for each planting date. The experimental unit was composed of two rows of five-meter length. Between and within rows spacing was $80 \mathrm{~cm} \times 50 \mathrm{~cm}$. NPK fertilizer at the rate of $100 \mathrm{~kg} / \mathrm{ha}$. Deltacal 12.5 EC (deltamethrin) and K-optimum 12.5 EC (deltamethrin + dimethoate) were applied to control insects' damage at flowering (Aphis craccivora and Maruca vitrata) and pod filling (Maruca vitrata, Megalurothrips sjostedti, and Clavigralla tomentosicollis).

2.3. Data Collection. In screen house trial, leaf chlorophyll content and seed weight were measured on individual plants and weather parameters such as relative humidity and temperature were daily recorded from 7 to $8: 30 \mathrm{AM}$ and from 1 to 2:30 PM throughout the stress period. For field experiment, days to $50 \%$ flowering and $95 \%$ maturity, 100 seeds weight, seeds yield in each plot, and rainfall data were recorded. Using the yield data collected, drought tolerance indices were calculated according to the following formula [17-19]:

$$
\begin{aligned}
\text { stress tolerance }(\mathrm{TOL}) & =Y_{p}-Y_{s}, \\
\text { mean productivity }(\mathrm{MP}) & =\frac{\left(Y_{p}+Y_{s}\right)}{2}, \\
\text { Stress Susceptibility Index (SSI) } & =\frac{\left(1-\left(Y_{s} / Y_{p}\right)\right)}{\mathrm{IS}},
\end{aligned}
$$




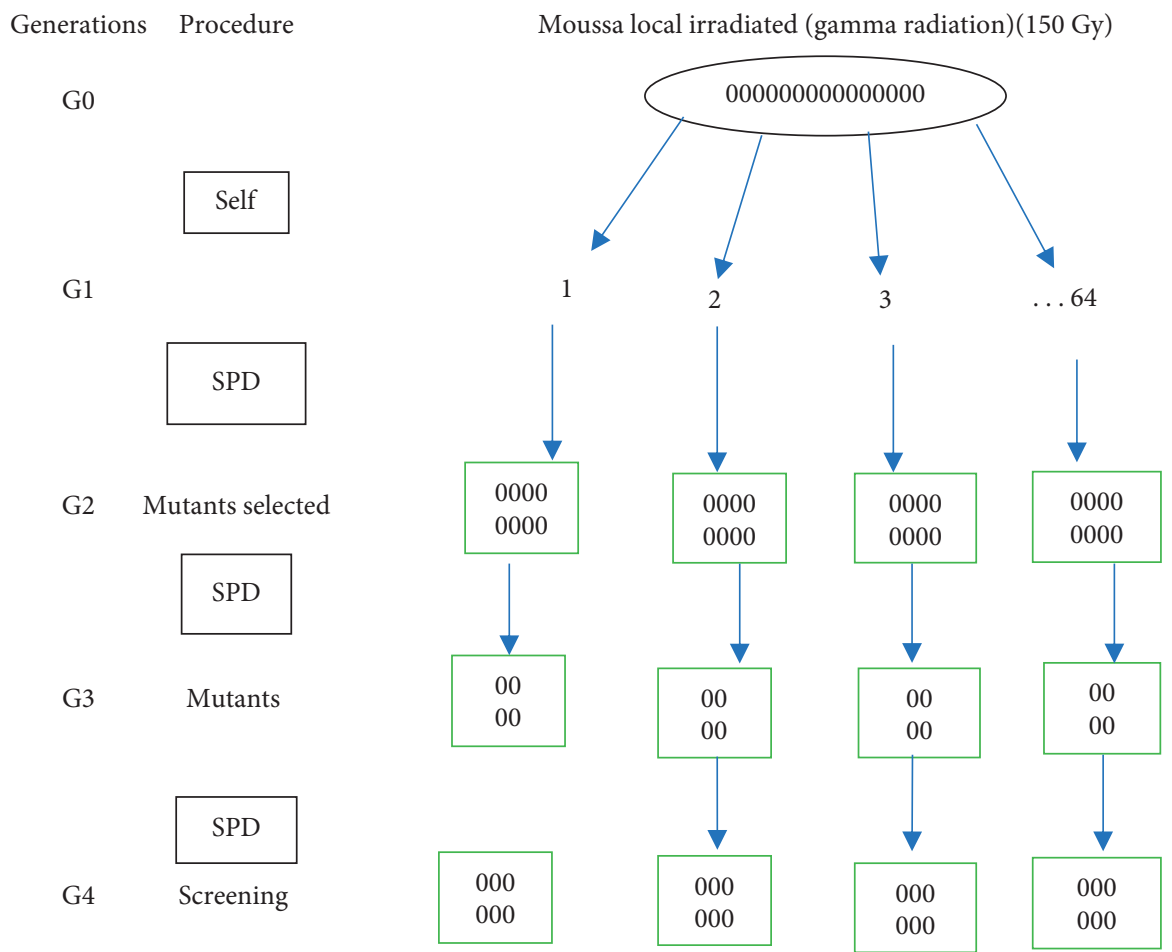

FIGURE 1: Schematic representation of the development of mutant lines. SPD: single plant descent; circles: individual plants; rectangles: lines.

$$
\text { Stress Tolerance Index }(\mathrm{STI})=\frac{\left(Y_{p} * Y_{s}\right)}{\left(\widehat{Y}_{p}\right)^{2}},
$$

where in these equations $Y_{s}$ and $Y_{p}$ are average yield of all genotypes under stress and optimal conditions, respectively. $\widehat{Y}_{s}$ and $\widehat{Y}_{p}$ are the mean yields over all genotypes evaluated under stress and nonstress conditions.

Stress intensity $(\mathrm{SI})$ is calculated as $\mathrm{SI}=\left[1-\left(\widehat{Y}_{s} / \widehat{Y}_{p}\right)\right]$, where SI $<25 \%$, water stress is lower; $25 \% \leq \mathrm{SI} \leq 50 \%$, stress is moderate; and SI $>50 \%$, stress is high.

2.4. Statistical Analysis. Analysis of variance and means separation by Student-Newman-Keuls test at $\alpha=5 \%$ were run using JMP software, version 14, 2018. The bivariate analysis such as Pearson's correlations test was done to determine relations between the drought tolerance indices and tolerant mutant. The multivariate statistical analyses such as principal component analysis to classify the drought tolerance indices and cluster analysis to determine the most desirable drought tolerance were performed using the same software.

\section{Results and Discussion}

3.1. Temperature and Relative Humidity. Daily minimum and maximum temperature and relative humidity of the screen house in the morning and afternoon during the experiment are represented in Figure 2. The mean temperature recorded from 7 to $8: 30 \mathrm{AM}$ was $36.47^{\circ} \mathrm{C}$; this mean was $39.91^{\circ} \mathrm{C}$ between 1 and 2:30 PM. The minimum was $30^{\circ} \mathrm{C}$ and maximum $42^{\circ} \mathrm{C}$. These average temperatures were not within favorable for cowpea grown temperature which varied between $22^{\circ} \mathrm{C}$ and $30^{\circ} \mathrm{C}$ [20]. The relative humidity means was $36.88 \%$ from 7 to $8: 30 \mathrm{AM}$ and it decreased to $20.69 \%$ from 1 to $2: 30$ PM. The lower value of relative humidity was observed after 1 PM. The result indicates that the environment condition was hot throughout the period of the experiment and the moisture was lower with high temperature. The study in [21] reported that high temperature in environment increased plant temperature implying high transpiration.

3.2. Rainfall Data in Kouare. Cowpea planting started in midJuly and it was harvested in September/October. Total rainfall (Figure 3) was $370.6 \mathrm{~mm}$ from July 18 to September 22, which corresponds to the experimentation time lapse of the first planting date. July 18 was the planting date and September 22 is the date corresponding to $95 \%$ maturity of pods. This rainfall was favorable to cowpea growth as reported by [20]. However, short and insufficient rainfall $(172.6 \mathrm{~mm})$ was registered from August 30 to the end of the rainy season on 3rd of October 2018, which corresponds to the experimental time of the second planting date. Plant flowering started on the 48th DAP in mid-October. The rainfall was lower comparatively to the normal which ranges from 200 to $350 \mathrm{~mm}$ [20]. The second planting date did not receive water (rain) during the flowering and pod maturity. The result indicates water deficiency for plants during this period. The rainfall was the main climatic factor limiting cowpea production after September.

3.3. Comparison of M5 Mutant Lines Behavior with Controls in Screen House and Identification of Tolerant M5 Mutant Lines. The results of analysis of variance for chlorophyll content and seed weight per plant (Table 1) showed significant 


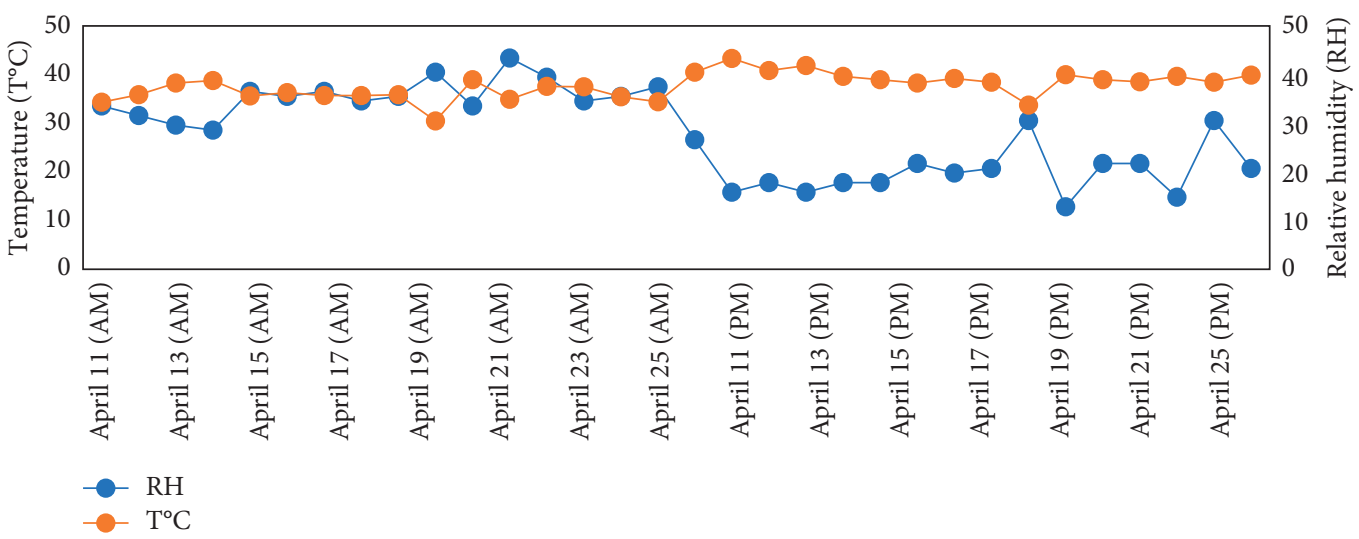

FIGURE 2: Variation of temperature and relative humidity in screen house during 16 days.



FIgURE 3: Evolution of rainfall in Kouare station during 2018 season.

difference under normal conditions, indicating the presence of genetic variation among the mutants and controls for these traits. The study revealed that cowpea mutants maintained in their leaves a level of chlorophyll content superior or like the nonirradiated control (Gorom local and Moussa local), whereas the nonirradiated lines (Gorom local and Moussa local) recorded the highest seeds weight. Under the 14 days' water stress conditions, plants of six mutant lines out of twelve have completely matured. These lines produced viable seeds after wilting stage. The nonirradiated controls (Gorom local and Moussa local) did not recover after the stress period.

Analysis of variance showed significant difference between the survived mutants under the water deficit conditions. This variability observed is essential for the improvement of the crop for drought tolerance. Under water stress, average chlorophyll content and seed weight decreased for about $61 \%$ and $29 \%$, respectively, as compared to the normal conditions. Therefore, water deficit stress induced significant chlorophyll loss. Similar observations were reported by [22]. In fact, water deficit decreases photosynthesis activity [23] leading to lower seeds' yield production. A reduction in seeds' production was also reported by [7] under water deficit. The overall effect of the drought stress depends on its intensity and the length of stress [24]. Drought effect is intensified with other climatic factors such as temperature. In fact, the temperature in screen house during the experiment often reached $42^{\circ} \mathrm{C}$. This temperature was higher than normal temperature supported by cowpea plants $\left(22^{\circ} \mathrm{C}\right.$ to $\left.30^{\circ} \mathrm{C}\right)$ [20]. In addition to the water deficit,
TABLE 1: Seed weight and chlorophyll content of mutant lines under nonstressed and stressed conditions.

\begin{tabular}{lccccc}
\hline Conditions & \multicolumn{2}{c}{ Nonstressed } & \multicolumn{3}{c}{ Stressed } \\
Mutants & Chl1 & SW & Chl1 & Chl2 & SW \\
& $(\%)$ & $(\mathrm{g})$ & $(\%)$ & $(\%)$ & $(\mathrm{g})$ \\
\hline MoussaM41-1P13 & $64.36 \mathrm{c}$ & $13.73 \mathrm{c}$ & $69.10 \mathrm{bc}$ & 20.90 & 20.97 \\
MoussaM43-20P14 & $80.21 \mathrm{a}$ & $10.71 \mathrm{~d}$ & $52.80 \mathrm{c}$ & 25.70 & 11.10 \\
MoussaM40-3P15 & $74.64 \mathrm{~b}$ & $10.70 \mathrm{~d}$ & $65.10 \mathrm{c}$ & 25.60 & 10.60 \\
MoussaM62-1P8 & $70.99 \mathrm{c}$ & $6.79 \mathrm{e}$ & $73.33 \mathrm{ab}$ & 34.00 & 9.57 \\
MoussaM51-4P10 & $80.75 \mathrm{a}$ & $9.92 \mathrm{de}$ & $75.80 \mathrm{a}$ & 34.80 & 8.48 \\
MoussaM62-1P4 & $74.77 \mathrm{~b}$ & $7.43 \mathrm{e}$ & $72.60 \mathrm{abc}$ & 26.30 & 6.10 \\
MoussaM62-1P3 & $68.19 \mathrm{~d}$ & $8.66 \mathrm{de}$ & $76.47 \mathrm{a}$ & 24.93 & 5.47 \\
MoussaM41-1P12 & $71.09 \mathrm{bc}$ & $15.08 \mathrm{~b}$ & & & \\
\hline Gorom local & $66.69 \mathrm{~cd}$ & $31.86 \mathrm{a}$ & & & \\
Moussa local & $65.89 \mathrm{~cd}$ & $24.34 \mathrm{~b}$ & & & \\
\hline Means & 71.87 & 14 & 71.44 & 28.45 & 9.96 \\
$R^{2}$ & $78 \%$ & $59 \%$ & $90 \%$ & $52 \%$ & $84 \%$ \\
P(5\%) & 0.016 & 0.003 & 0.024 & 0.556 & 0.06 \\
\hline
\end{tabular}

Chl: chlorophyll; SW: seed weight; g: gram; and a, b, c, and d: the values followed by the same letters are not significantly different at the threshold of $5 \%$.

the high temperature could have affected the development of the checks (Moussa local and Gorom local), which all died. In contrast, mutant lines were able to maintain chlorophyll content in leaves and produced seeds after normal watering resumed. Therefore, the mutant lines could have developed a mechanism to avoid water stress. Such mechanism of avoidance allowing plants to withstand a period of drought stress was reported by [15] in cowpea mutant lines irradiated 
with $180 \mathrm{~Gy}$ gamma rays. It can be inferred that gamma radiation $150 \mathrm{~Gy}$ enhanced photosynthetic performance in cowpea. This corresponds to the findings of [23] indicating that low doses of gamma radiation enhance chlorophyll content even photosynthetic activity. However, some perturbations have been reported in photosynthetic performance in chickpea by gamma radiation [25]. Indeed, the effects of the irradiation depend on doses and crops. In this study, six mutant lines were selected as resistant to water stress. Two lines, namely, MoussaM25-1P10 and MoussaM25-10P2, did not flower and would therefore express photosensitivity which is not an initial characteristic of the irradiated variety Moussa local.

3.4. Comparison of M6 Mutant Lines Behavior with Controls in Field Conditions and Identification of Tolerant M6 Mutant Lines. Result of variance analysis for agronomical traits under normal conditions revealed highly significant difference between mutants except days to $95 \%$ maturity and yield. Similar results were observed in water deficit conditions except days to $50 \%$ flowering and days to $95 \%$ maturity (Table 2). The mean yield was reduced for $31 \%$ under water stress conditions as compared to normal conditions implying the reduction of seeds production under water stress. Newman-Keuls test grouped the mutants into eight (8) groups based on seed yield under stressed conditions suggesting difference in their reactions to water deficit (Figure 4). In water stress conditions, mutant line MoussaM51$4 \mathrm{P} 10$ recorded $55 \%$ higher yield as compared to the resistant check Gorom local and over $100 \%$ to the susceptible check Moussa local. The mutant MoussaM51-4P10 did not record yield reduction. This mutant line had the highest yielding in stress condition. Moreover, mutant line MoussaM43-20P14 had $61 \%$ higher yield than Moussa local yield but like Gorom local yield. Thus, MoussaM43-20P14 had better yield performance than Moussa local under water stress conditions. This line recorded lower percentage of yield reduction caused by drought, suggesting yield stability. MoussaM43$20 \mathrm{P} 14$ could equally perform in nonstressed and stressed environments. On the other hand, MoussaM62-1P3, MoussaM10-4P7, MoussaM62-1P8, MoussaM62-1P4, MoussaM41-1P13, and Moussa local presented the higher percentage of yield reduction caused by drought; these lines produced seeds only under nonstressed conditions. These results reveal that the mutant MoussaM51-4P10 was extremely drought tolerant and promising line for production in dry season and MoussaM43-20P14 would be the most stable in nonstressed and stressed conditions. The mutant lines MoussaM41-4P4T, MoussaM25-1P14T, and MoussaM41-4P18T used as complementary material showed good performance under water stress conditions. These lines could be assessed in other studies to confirm their tolerance to drought. The differential response to water stress would indicate different tolerant abilities of mutant lines.

In general, hundred seed weight was higher under water stress conditions (Figure 5), suggesting that the photosynthetic activity is important at the end of season due to the sunlight in the period of September. That indicates the importance of sunlight for seed size determination. Except MoussaM43-20P14, MoussaM41-1P13, and MoussaM41$1 \mathrm{P} 14 \mathrm{~T}$, all the mutant lines recorded higher hundred seeds' weight in stress conditions. The mutant line MoussaM514P10, MoussaM25-1P14T, and MousM51-4P6T recorded the highest hundred seed weight in the same conditions. Among them, MoussaM51-4P10 registered the highest yield. In fact, seed weight is the major component of grain yield, explaining the high yield observed for these genotypes. Therefore, high hundred seeds' weight is an important component that should be considered in plant breeding to improve grain yield. The results also indicated that there was large genetic diversity between mutant and control.

The result did not show variation in days to maturity among mutants and the checks in both nonstressed and stressed conditions implying that the irradiation did not affect plant maturity cycle. However, it has been reported that the occurrence of water stress at reproduction stage reduced the number of days to physiological maturity [26]. From this study, gamma irradiation induced genetic diversity and enhanced yields' seed, but it did not reduce in days taken to reach maturity of cowpea.

3.5. Determination of Drought Tolerance Indices. Results of stress tolerance indices calculated are presented in Table 3. The result revealed that the lines with the low SSI value that can be considered have water stress tolerance because they recorded small yield reduction under water stressed as compared to nonstressed condition. A genotype with SSI value smaller than one (1) is considered as tolerant to drought [18]. It was observed that seven mutant lines which had SSI value less than one (1). Among them, mutant lines MoussaM43-20P14 and MoussaM41-4P4T had the lowest positive value. The mutant MoussaM51-4P10, MoussaM41-4 P18T, and MoussaM41-1P14T had negative value of SSI. Therefore, these lines were drought tolerant. However, the selection based on SSI did not differentiate line with high yield from those with low yield. However, changes caused by drought stress to genotypes can be captured through Tolerance Index (TOL). The lower level of TOL index shows less change and reveals a high relative tolerance [27]. The mutant lines MoussaM51-4P10, MoussaM41-4 P18T, and MoussaM41-1P14T had negative TOL value implying more yield under stress conditions than nonstress conditions. The mutant MoussaM43-20P14 and MoussaM41-4P4T recorded the lowest positive TOL value. These mutants were tolerant to water stress. The Stress Tolerance Index (STI) values of the mutant lines MoussaM51-4P10, MoussaM41-4P4T, and MoussaM25-1P14T were higher than the others and they also exhibited higher value of mean productivity (MP). These lines were found to be tolerant to water stress. Genotypes combining low SSI and TOL, high MP and STI can be considered as drought-resistant genotypes under moderate drought with SI equal to $35 \%$. Therefore, from this study and based on SSI, TOL, and STI indices and MP, mutants MoussaM51-4P10 and MoussaM41-4P4T could be considered as the most drought tolerant and highest yielding under water deficient conditions. Mutants MoussaM43- 
TABLE 2: Results of analysis of variance of parameters measured under nonstressed and stressed conditions.

\begin{tabular}{lcccccccccc}
\hline \multirow{2}{*}{ Parameters } & \multicolumn{9}{c}{ Nonstressed } & \multicolumn{3}{c}{ Stressed } \\
& DPF & $50 \% \mathrm{~F}$ & $95 \% \mathrm{M}$ & $100 \mathrm{SW}$ & $Y_{p}$ & $\mathrm{DPF}$ & $50 \% \mathrm{~F}$ & $95 \% \mathrm{M}$ & $100 \mathrm{SW}$ & $Y_{s}$ \\
\hline Mean & 44.28 & 48.55 & 85.47 & 17.47 & 559.7 & 42.97 & 48.26 & 68.05 & 18.34 & 361.83 \\
$R^{2}$ & 0.65 & 0.62 & 0.33 & 0.53 & 0.3 & 0.36 & 0.68 & 0.46 & 0.58 & 0.62 \\
Prob $(0.05)$ & $\mathbf{0 . 0 0 0 6}$ & $\mathbf{0 . 0 0 2}$ & 0.4764 & $\mathbf{0 . 0 2 1 5}$ & 0.5896 & 0.3644 & $\mathbf{0 . 0 0 0 3}$ & 0.1169 & $\mathbf{0 . 0 0 8 4}$ & $\mathbf{0 . 0 0 2 6}$ \\
\hline
\end{tabular}

SWp: seed weight in nonstressed conditions (gram); SWs: seed weight in stressed conditions (gram); $Y_{p}$ : yield in nonstressed conditions (gram); and $Y_{s}$ : yield in stressed conditions (gram).



FIGURE 4: Yield performance of mutant and controls under nonstressed and stressed conditions. $Y_{p}$ : yield in nonstressed conditions (gram); $Y_{s}$ : yield in stressed conditions (gram).

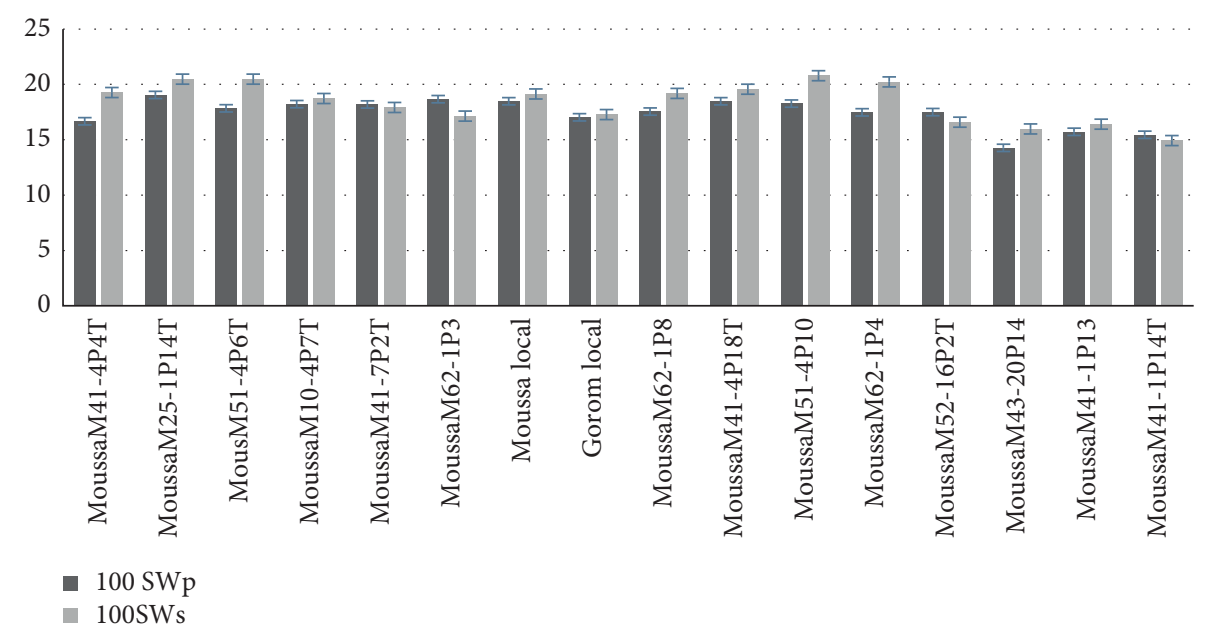

FIGURE 5: Hundred seed weight of mutant and controls under nonstressed and stressed conditions. SWp: seed weight in nonstressed conditions; SWs: seed weight in stressed conditions.

20P14, MoussaM41-4P4T, and Gorom local which recorded lower SSI and TOL value and moderate STI and PM value are relatively drought tolerant under moderate water stress. The susceptibility of the susceptible check Moussa local was confirmed based on the same indices.

3.6. Correlation between Traits. Genotypic correlation coefficient between yield under nonstressed $\left(Y_{p}\right)$ and stressed
$\left(Y_{s}\right)$ conditions and other quantitative indices of drought tolerance are presented in Table 4 . The results showed moderate water stress conditions $(\mathrm{SI}=35 \%)$, negative correlations between seed yield in nonstress conditions and seed yield in water stress conditions, indicating that high yield potential under best conditions does not imply superior yield under stress conditions. Positive and significant associations have also been observed between grain yield in nonstressed condition with MP $\left(r=0.66^{*}\right)$ and STI 
TABLE 3: Estimates of drought tolerance indices of cowpea mutant under normal and stressed conditions.

\begin{tabular}{|c|c|c|c|c|c|c|}
\hline Genotypes & $Y_{p}$ & $Y_{s}$ & PM & TOL & SSI & STI \\
\hline MoussaM41- 24P4T & $625.07 a$ & $600.55 \mathrm{ab}$ & 612.81 & 24.52 & 0.11 & 1.20 \\
\hline MoussaM25-1P14T & $817.90 a$ & $434.60 \mathrm{abcd}$ & 626.25 & 383.30 & 1.34 & 1.13 \\
\hline MousM51-4P6T & $708.54 \mathrm{a}$ & 373.79 cde & 541.17 & 334.75 & 1.35 & 0.85 \\
\hline MoussaM10-4P7 & $699.26 a$ & $220.25 \mathrm{de}$ & 459.76 & 479.01 & 1.96 & 0.49 \\
\hline MoussaM41-7P2T & $681.80 a$ & 240.70 de & 461.25 & 441.10 & 1.85 & 0.52 \\
\hline MoussaM62-1P3 & $674.40 \mathrm{a}$ & $245.40 \mathrm{de}$ & 459.90 & 429.00 & 1.82 & 0.53 \\
\hline Moussa local & $533.37 \mathrm{a}$ & $269.21 \mathrm{de}$ & 401.29 & 264.16 & 1.42 & 0.46 \\
\hline Gorom local & $533.09 a$ & 433.79abcd & 483.44 & 99.30 & 0.53 & 0.74 \\
\hline MoussaM62-1P8 & $532.10 \mathrm{a}$ & $277.24 \mathrm{de}$ & 404.67 & 254.86 & 1.37 & 0.47 \\
\hline MoussaM41-4P18T & $510.70 \mathrm{a}$ & $545.17 \mathrm{abc}$ & 527.94 & -34.47 & -0.19 & 0.89 \\
\hline MoussaM51-4P10 & $505.18 \mathrm{a}$ & $673.80 \mathrm{a}$ & 589.49 & -168.62 & -0.95 & 1.09 \\
\hline MoussaM62-1P4 & $465.97 a$ & $321.68 \mathrm{de}$ & 393.83 & 144.29 & 0.88 & 0.48 \\
\hline MousM52-16P2T & $458.77 a$ & $161.45 \mathrm{e}$ & 310.11 & 297.32 & 1.85 & 0.24 \\
\hline MoussaM43-20P14 & $457.23 \mathrm{a}$ & 434.13abcd & 445.68 & 23.10 & 0.14 & 0.63 \\
\hline MoussaM41-1P13 & $411.30 \mathrm{a}$ & $222.40 \mathrm{de}$ & 316.85 & 188.90 & 1.31 & 0.29 \\
\hline MoussaM41-1P14T & $291.16 a$ & $398.56 \mathrm{bcd}$ & 344.86 & -107.40 & -1.05 & 0.37 \\
\hline
\end{tabular}

MP: mean productivity; TOL: stress tolerance, SSI: Stress Susceptibility Index, STI: Stress Tolerance Index; $Y_{p}$ : yield in nonstress condition, $Y_{s}$ : yield in stress condition; $a, b, c$, and $d$ : the values followed by the same letters are not significantly different at the threshold of $5 \%$.

TABLE 4: Correlation between drought tolerance indices and seed yield under nonstressed and water deficient stressed conditions.

\begin{tabular}{lcccccc}
\hline & $Y_{p}$ & $Y_{s}$ & PM & TOL & SSI & STI \\
\hline$Y_{p}$ & 1 & & & & & \\
$Y_{s}$ & -0.0242 & 1 & & & & \\
PM & $0.662^{*}$ & $0.7333^{*}$ & 1 & & & \\
TOL & $0.6817^{*}$ & $-0.748^{*}$ & -0.0972 & 1 & & \\
SSI & $0.5428^{*}$ & $-0.8146^{*}$ & -0.2416 & $0.9566^{*}$ & 1 & \\
STI & $0.4908^{*}$ & $0.8474^{*}$ & 0.9691 & -0.2943 & -0.4035 & 1 \\
\hline
\end{tabular}

MP: mean productivity; TOL: stress tolerance, SSI: Stress Susceptibility Index, STI: Stress Tolerance Index; $Y_{p}$ : yield in nonstress condition; and $Y_{s}$ : yield in stress condition. * Significant at $5 \%$.

$\left(r=0.45^{*}\right)$ and strong significant positive correlation between grain yield in stressed condition with MP $\left(r=0.73^{*}\right)$ and STI $\left(r=0.85^{*}\right)$. Thus, MP and STI indices are particularly good criteria to select genotypes with high yield potential in water stress conditions. These results are contrasting with those reported by [28], indicating that selection based on STI index and means productivity would improve cowpea yield under nonstress and stress conditions. Seed yield in nonstress condition $\left(Y_{p}\right)$ was positively and significantly associated with TOL index $\left(r=0.68^{*}\right)$ and SSI index $\left(r=0.54^{*}\right)$ while seed yield in stress condition $\left(Y_{s}\right)$ was negatively and significantly correlated with TOL $\left(r=-0.75^{*}\right)$ and SSI $\left(r=-0.81^{*}\right)$. These results suggested that selection based on SSI and TOL index increases yield only under nonstress condition. Thus, the low values of SSI and TOL could be useful to select water stress tolerant in cowpea mutant with high yield.

3.7. Variability Organization. Results of the relationships between tolerance indices through the principal component analysis are presented in Table 5. The first component justified $58 \%$ of variability. On this component, seed yield Ys, MP, and STI indices had the highest coefficients confirming that the high value of MP and STI indices indicate high-yielding and drought-tolerant genotypes. In consequence, the mutant which has a high value of STI and PM is suitable for dry areas. The results indicated that the indices MP and STI were equal for selecting drought-tolerant genotypes. Therefore, the Stress Tolerance Index (STI) can be useful to select water stress tolerance. The study in [16] reported that a selection based on the Stress Tolerance Index (STI) allows to identify genotypes with high yield under stress conditions. Similar results have been reported by [29] in spring wheat improvement. This finding is like the result of [19]. The second PCA, with $98 \%$ of the total of variability, had high positive correlation with $Y_{p}$, SSI, and TOL. The higher values of TOL and SSI are the most important criteria to select favorite genotypes with high yield under nonstress conditions. The lower values of these indices are suitable factors to identify tolerant mutant lines to water stress with high yield in stress conditions.

3.8. Genotypes Structuration. Cluster analysis revealed that mutant lines and the controls were grouped into two clusters (Figure 6). Cluster I was composed of five genotypes (MoussaM51-4P10, MoussaM41-4P4T, MoussaM43-20P14, MoussaM41-4P18T, and Gorom local), which had high yield under moderate stress conditions, high value of STI, and low SSI index. MoussaM51-4P10 and MoussaM41-4P4T were different from MoussaM43-20P14 and Gorom local in terms of drought tolerance. MoussaM51-4P10 and MoussaM41-4P4T had the highest value of STI and the lowest value of SSI. They are strong tolerant genotypes to water stress. MoussaM4320P14 and Gorom local could be moderately tolerant genotypes as regards the results reported by [16] on Gorom local. Cluster II comprised eleven lines among MoussaM62-1P3, MoussaM62-1P4, MoussaM62-1P8, MoussaM41-1P13, and Moussa local. They are characterized by their high yielding potential under well-watered conditions. These genotypes are drought susceptible. The different characteristics of the two 
TABLE 5: Eigenvalue and vectors of principal component analysis for potential yield (YP), stress yield (YS), and stress tolerance indices.

\begin{tabular}{lcccccccc}
\hline Component & $Y_{p}$ & $Y_{s}$ & PM & TOL & SSI & STI & Cumulative \% & Eigenvalue \\
\hline 1 & -0.24 & 0.53 & 0.38 & -0.41 & -0.45 & 0.45 & 58 & 3.5 \\
2 & 0.64 & 0.01 & 0.44 & 0.41 & 0.33 & 0.34 & 98 & 2.4 \\
\hline
\end{tabular}

MP: mean productivity; Tol: stress tolerance, SSI: Stress Susceptibility Index, STI: Stress Tolerance Index; $Y_{p}$ : yield in nonstress condition; and $Y_{s}$ : yield in stress condition.

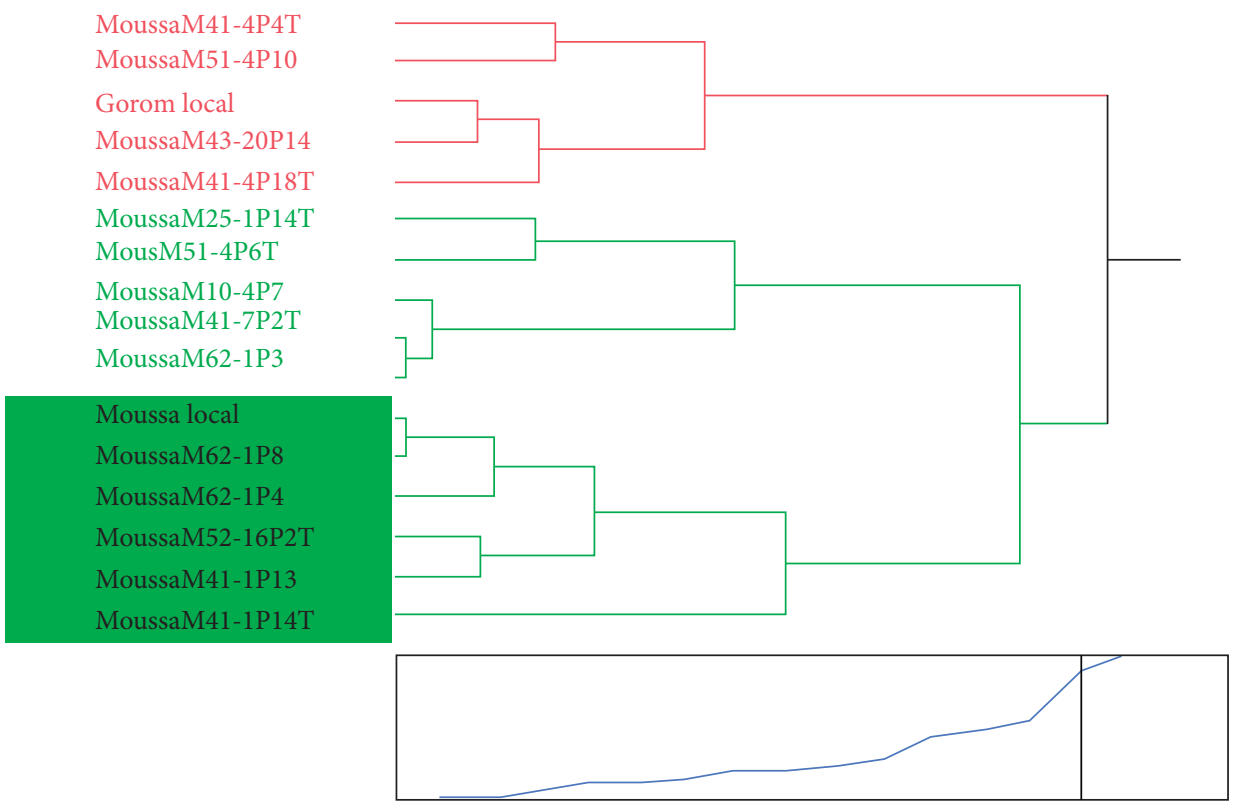

FIgURE 6: Dendrogram showing the two clusters based on MP, STI, TOL, SSI indices and yield of the tested genotypes.

classes showed a considerable genetic variability among mutant lines for drought tolerance. These results confirmed that gamma radiation, at $150 \mathrm{~Gy}$, induced drought tolerance in some mutant lines. Similar results have also been reported in cowpea mutants by $[15,23]$. Therefore, mutation can be acknowledged as an efficient way for reducing drought tolerance in cowpea genotypes.

\section{Conclusion}

Water stress affects grain yield during the rainy season in sub-Saharan Africa. High and useful genetic diversity for drought tolerance was induced into the cowpea mutant lines through gamma irradiation. Among these mutant lines, high drought tolerance with higher yield potential in water stress conditions as compared to optimal conditions was identified. Mutant line MoussaM51-4 P10 had the best yield performance under water deficit conditions. Mutant line MoussaM43-20P14 was as better as the tolerant check Gorom Local under water stress conditions. These two mutant lines, namely, MoussaM51-4 P10 and MoussaM43-20P14, were the best drought tolerant and are good candidate for further evaluation to release or use as donor parents in cowpea improvement program for drought tolerance. Stress Tolerance Index (STI) can be used as the most suitable indicator for screening cowpea genotypes for drought tolerance.

\section{Data Availability}

The data used to support the findings of this study are available from the corresponding author upon request.

\section{Disclosure}

This research is part of a Ph.D.'s thesis called "Amélioration Variétale du Niébé (Vigna unguiculata (L.) Walp.) pour la Resistance au Striga et au Stress Hydrique par l'Utilisation des Mutants au Burkina Faso" [30].

\section{Conflicts of Interest}

The authors declare no conflicts of interest regarding the publication of this paper.

\section{Authors' Contributions}

This work was carried out in collaboration between both authors. The first author designed the experiment and analyzed the data. Both of the authors interpreted the data, read the final manuscript, and agreed with all contents.

\section{Acknowledgments}

The authors gratefully acknowledge the financial support provided by ICRISAT/TLLIII. The authors acknowledge 
IAEA for irradiating the cowpea seeds used in this study. They are also thankful to all team members of INERA and of the "Laboratoire Biosciences" of the "Université Joseph KIZERBO” for their input in this manuscript.

\section{References}

[1] N. B. Boukar, S. Chamarthi, A. Togola et al., "Cowpea (Vigna unguiculata): genetics, genomics and breeding," Plant Breed, vol. 138, pp. 415-424, 2018.

[2] FAOSTAT, http://www.fao.org/faostat, 2018.

[3] B. Ibrahim, "Caractérisation des saisons de pluies au Burkina Faso dans un contexte de changement climatique et évaluation des impacts hydrologiques sur le bassin du Nakanbé," Universite Pierre Et Marie Curie- Paris VI, Paris, France, Thèse de Doctorat, 2012.

[4] I. Masih, S. Maskey, F. E. F. Mussá, and P. Trambauer, “A review of droughts on the African continent: a geospatial and long-term perspective," Hydrology and Earth System Sciences, vol. 18, no. 9, pp. 3635-3649, 2014.

[5] J. Ajetomobi and A. Abiodun, "Climate change impacts on cowpea productivity in Nigeria," AJFAND, vol. 10, pp. 2258-2271, 2010.

[6] M. Farooq, N. Gogoi, S. Barthakur et al., "Drought stress in grain legumes during reproduction and grain filling," Journal of Agronomy and Crop Science, vol. 203, no. 2, pp. 81-102, 2017.

[7] T. D. A. Karim, A. Sanoussi, I. M. Maârouh, H. Falalou, and B. Yacoubou, "Effect of water deficit at different stages of development on the yield components of cowpea (Vigna unguiculata L. Walp) genotypes," African Journal of Biotechnology, vol. 17, pp. 279-287, 2018.

[8] W. Amri-Tilioune, M. Laouar, A. Abdelguerfi, J. JankowiczCieslak, L. Jankuloski, and B. J. Till, "Genetic variability induced by gamma rays and preliminary results of low-cost telling on M2 generation of chckpea (Cicer arietinum L.)," Frontier Plant Sciences, vol. 9, p. 1568, 2018.

[9] B. J. T. Batieno, O. Souleymane, J. B. Tignegre et al., "Single nucleotide polymorphism (SNP)-based genetic diversity in a set of Burkina Faso cowpea germplasm," African Journal of Agricultural Research, vol. 13, pp. 978-998, 2018.

[10] F. O. Olasupo, C. O. Ilori, B. P. Forster, and S. Bado, "Selection for novel mutations induced by gamma irradiation in cowpea [Vigna unguiculata (L.) Walp.]," International Journal of Plant Breeding and Genetics, vol. 12, no. 1, pp. 1-12, 2018.

[11] A. Micke, "Mutation breeding of grain legumes," Enhancement of Biological Nitrogen Fixation of Common Bean in Latin America, vol. 52, pp. 81-85, 1993.

[12] A. Gunasekaran and P. Pavadai, "Studies on induced physical and chemical mutagenesis in groundnut (Arachis hypogia)," International Letters of Natural Sciences, vol. 35, pp. 25-35, 2015.

[13] K. Gnankambary, T. B. J. Batieno, N. Sawadogo et al., "Genetic variability induced by gamma radiation in cowpea [(Vigna unguiculata L. (Walp)] in Burkina Faso," European Scientific Journal, vol. 15, pp. 154-164, 2019a.

[14] K. Gnankambary, T. B. J. Batieno, N. Sawadogo et al., "Assessment of radio-sensitivity for three cowpea genotype to gamma irradiation," International Journal of Genetics and Molecular Biology, vol. 11, pp. 29-33, 2019b.

[15] J. A. Ronde and R. M. H. Spreeth, "Development and evaluation of drought resistant mutant germoplasm of Vigna unguculata," Water SA, vol. 33, pp. 381-385, 2007.
[16] B. J. Batieno, J. B. Tignegre, H. Sidibe et al., "Field assessment of cowpea genotypes for drought tolerance," International Journal of Sciences: Basic and Applied Research, vol. 30, pp. 358-369, 2016.

[17] A. A. Rosielle and J. Hamblin, "Theoretical aspects of selection for yield in stress and non-stress environment 1," Crop Science, vol. 21, no. 6, pp. 943-946, 1981.

[18] R. Fischer and R. Maurer, "Drought resistance in spring wheat cultivars. I. Grain yield responses," Australian Journal of Agricultural Research, vol. 29, no. 5, pp. 897-912, 1978.

[19] G. C. J. Fernandez, "Effective selection criteria for assessing plant stress tolerance," in Proceedings of The International Symposium on Adaptation of Vegetable and Other Food Crops in Temperature and Water Stress, Taiwan, China, August 1992.

[20] B. B. Singh, Cowpea, the food legume of the $21^{e}$ century, Crop Science Society of America, Fitchburg, Wisconsin, 2014.

[21] H. Abou, H. Falalou, H. Oumarou, B. F. Achirou, and B. Yacouba, "Réponse physiologique des génotypes de niébé (Vigna unguiculata (L.)) au déficit hydrique en conditions de lysimètre et performance agronomique au champ," IOSR Journal of Agriculture and Veterinary Sciences, vol. 12, pp. 22-33, 2019.

[22] S. E. Mwale, M. Ochwo-Ssemakula, K. Sadik et al., "Response of cowpea genotypes to drought stress in Uganda," American Journal of Plant Sciences, vol. 8, no. 4, pp. 720-733, 2017.

[23] H. Moussa, "Low dose of gamma irradiation enhanced drought tolerance in soybean," Bulgarian Journal of Agricultural Science, vol. 17, pp. 63-72, 2011.

[24] N. M. Bukhat, "Studies in yield and yield associated traits of wheat (triticum aestivum L.) genotypes under drought conditions," M.Sc thesis, Department of Agronomy. Sindh Agriculture University, Tandojam, Pakistan, 2005.

[25] I. Brahmi, Y. Mabrouk, K. Charaabi, P. Delavault, P. Simier, and O. Belhadj, "Induced mutagenesis through gamma radiation in chickpea (Cicer arietinum L.): developmental changes and improved resistance to the parasitic weed Orobanche foetida poir," International Journal of Advanced Research, vol. 2, pp. 670-684, 2014.

[26] C. A. Fatokum, O. Boukar, and S. Muranaka, "Evaluation of cowpea (Vigna unguiculata (L.) Walp.) germplasm lines for tolerance to drought," Plant Genetic Ressorces, vol. 10, pp. 171-176, 2012.

[27] K. H. Mafakheri, M. R. Bihamta, and A. R. Abassi, "Screening for drought stress tolerance in cowpea genotypes (Vigna unguculata L.)," Iranian Journal of Pulses Research, vol. 6, pp. 123-138, 2015.

[28] S. E. Mwale, M. Ochwo-Ssemakula, K. Sadik, P. Rubaihayo, P. Gibson, and R. Edema, "Post flowering drought tolerance in cowpea genotypes in Uganda," Ruforum Working Document Series, vol. 13, pp. 123-128, 2016.

[29] N. Orcen and M. Altinbas, "Use of some stress tolerance indices for late drought in spring wheat," Fresenius Environmental Bulletin, vol. 23, pp. 2289-2293, 2014.

[30] K. Gnankambary, “Amélioration variétale du niébé (Vigna unguiculata (L.) Walp.) pour la résistance au striga et au stress hydrique par l'utilisation des mutants au Burkina Faso," Ph D. thesis, Université Joseph KI-ZERBO, Ouagadougou, Burkina Faso, 2019. 